\title{
A Educomunicação como alternativa para criação de ecossistemas comunicativos nas organizacões: uma análise do Programa "Veja na Sala de Aula"
}

\author{
Regiane Regina Ribeiro ${ }^{1}$ \\ (regianeribeiro5@gmail.com)
}

\begin{abstract}
Resumo
$\mathrm{O}$ artigo tem como tema o estabelecimento da conexão entre conceito e prática da responsabilidade social e ações na interface comunicação/educação. Entendendo a Educomunicação como processo de ampliação do coeficiente comunicativo de modo a construir ecossistemas abertos e democráticos, este trabalho objetiva, com tal perspectiva, uma alternativa para que as empresas promovam espaços significativos e humanizados formando e transformando os públicos em sujeitos críticos e inseridos no seu próprio meio social. Através da metodologia do estudo de caso, o artigo analisa o Programa "Veja na Sala de Aula" e conclui que a iniciativa é pertinente, mas apresenta aspecto limitador e reducionista nas ações propostas de utilização da mídia na escola.
\end{abstract}

Palavras-Chave: Educomunicacão. Responsabilidade social. Organizações.

\begin{abstract}
The article has as main theme the establishment of the connexion between social responsability practice and concept and the actions in the communication/education interface. Understanding the educommunication as the process that amplifies the communicative coefficient in order to build open and democratic ecosystems, this works aims, with such perspective, an alternative for the enterprises to promote significant and humanized spaces that forms and transforms the public into critical actors inserted in their own social environment. Through the case study methodology, the article analyses the program "Veja na Sala de Aula" and concludes that it is a pertinent iniciative, but that it presents a limitative and reductionist aspect in its actions for the use of the media the school
\end{abstract}

Keywords: Educommunication. Social responsability. Organizations.

\section{Introdução}

Sabe-se que nas últimas décadas as organizações têm vivenciado uma grande mudança em seu cenário. Elas deixaram de ser vistas como instituições econômicas com responsabilidades referentes à produção e lucratividade e assumiram novos papéis. De acordo com Ashen (1970) apesar do visível sucesso obtido pelo sistema capitalista, em conseqüência de uma eficiente combinação de ciência e tecnologia e de uma eficaz administração de recursos - quando se confrontam os resultados econômicos e monetários com resultados sociais, tais como redução da

\footnotetext{
${ }^{1}$ Doutora em Comunicação e Semiótica pela PUC-SP. Professora e pesquisadora permanente do Programa de Mestrado em Comunicação da Universidade Federal do Paraná - UFPR, na linha de pesquisa Comunicação, Educação e Formações Socioculturais. Docente do curso de Comunicação Social da Universidade Federal do Paraná.
} 
pobreza, analfabetismo, degradação das áreas urbanas, controle da poluição, diminuição das iniqüidades sociais, entre outros, percebe-se que ainda há muito por fazer.

Buchholz (1989) afirma que as organizações voltam-se cada vez mais para problemas que vão além dos aspectos econômicos, atingindo um espectro muito mais amplo. Como resultado da ampliação desse contexto tem proliferado a pressão social, através de movimentos sociais reivindicatórios feitos por grupos organizados, que resultam em novas leis e regulamentações e provocam modificações nas regras do jogo. Tais mudanças afetam de forma intensa o ambiente social e político em que a empresa atua, criando novas diretrizes e limitações para operar de forma eficaz, segundo essa nova ótica.

Nessa tentativa de atuar dentro desse ambiente mais social e humanizado as organizações buscam estratégias e ações que possam legitimar essa visão. Surgem assim os programas de responsabilidade social que, segundo Bueno (2003, p 106), podem ser definidos como o exercício planejado e sistemático de ações, estratégias e a implementação de canais de relacionamentos entre organização, públicos e a própria sociedade.

Levando em consideração tais princípios, as organizações passam a tentar atuar dentro destas perspectivas e vêem na educação uma das interfaces possíveis para que esses objetivos sejam alcançados. No entanto, percebe-se que apesar de muitos projetos na área de educação estarem sendo desenvolvidos, ainda assim, existem poucas pesquisas nessa interface. Isso dificulta o entendimento do campo e impossibilita as organizações de fazerem uso dessas ferramentas ao seu favor e a favor dos públicos com os quais elas se relacionam.

Outro ponto questionado é a tendência que esses programas e ações desenvolvidos ou apoiados pelas organizações têm em privilegiar o fortalecimento da imagem organizacional a uma perspectiva de comprometimento, cooperação, interesse público e transformação social. Dessa forma, o artigo propõe uma discussão teórica que aponta a Educomunicação como ferramenta para que as organizações possam modificar esse cenário e analisa criticamente o Programa "Veja na Sala de Aula" enquanto proposta educomunicativa empírica de uma organização privada.

\section{Responsabilidade social, Comunicação e Educação}

O tema da atuação social das organizações tem recebido tanto da mídia quanto da literatura mais especializada, um difuso e controverso conjunto de definições ambíguas e inconclusas. Os termos Cidadania Empresarial, Marketing Social, Accountability, Responsabilidade Social e Responsabilidade Corporativa são empregados de forma indistinta. Segundo Borger (2001, p.30), a 
ação social e investimento social privado são denominações mais modernas, que procuram distinguir-se de filantropia empresarial, conceito que, por sua vez, é associado às noções de caridade e assistencialismo, consideradas obsoletas e inadequadas.

A grande discussão sobre o âmbito social nas organizações surge com a obra Social Responsabilities of the Businessman (1953) de Howard Bowen. O autor definiu a responsabilidade social como a obrigação das organizações em perseguir políticas, tomar decisões e seguir linhas de ação em consonância com objetivos e valores desejáveis pela sociedade, e defendeu a ideia de que haveriam outros objetivos empresariais além do lucro, portanto as organizações deveriam alargar o escopo de suas responsabilidades.

Essa visão ganha mais força na década de 70, quando as empresas são obrigadas a avaliar os efeitos sociais de suas decisões deixando de buscar apenas vantagens econômicas. Além disso, a responsabilidade social empresarial se diferencia nesse momento das obrigações legais, possibilitando situar a responsabilidade social como ações que começam onde termina a lei.

Carroll (1979) formula uma importante e abrangente teoria, a qual compreende a responsabilidade social em quatro categorias não excludentes. A primeira categoria é a econômica, na qual a empresa deve buscar o lucro. A segunda, a ética, na qual o objetivo é preocupar-se com a moral e a ética de suas ações. Na categoria legal, a organização deve respeitar e obedecer as leis e na categoria filantrópica ou discricionária, a empresa deve considerar a sociedade e o meio no qual está inserida.

Preston (1975), a partir do desenvolvimento do trabalho de Bowen, delimitou três principais correntes teóricas sobre a atuação social doas organizações: a institucionalista, a organizacional e a filosófica.

A teoria institucionalista relaciona a organização em um universo social mais amplo. As contribuições teóricas situadas no campo organizacional compreendem a relação organizaçãosociedade em um universo localizado no âmbito das organizações, regidas, principalmente, pela eleição da estratégia como instrumento destinado a promover a adaptação das corporações às mudanças ambientais e a teoria filosófica tem base em concepções teóricas prescritivas com relação à responsabilidade social, estando aí situadas posições de cunho neoliberal, filantrópicas e de maior comprometimento com questões sociais por parte das corporações.

Todas essas definições, no entanto, convergem coma afirmação de Wartick e Cochran, (1985), a qual afirma que as organizações devem a razão de sua existência a um contexto social e que são agentes sociais que refletem e reforçam valores (WARTICK; COCHRAN, 1985, p. 758). 
Sendo assim, a busca por uma nova fora de desenvolvimento, que tenha como eixos principais a dimensão humana e a harmonia com os ecossistemas, deve partir da premissa que os indivíduos, devem adotar comportamentos de consumo mais compatíveis com o meio ambiente e, como cidadãos, devem ter consciência do seu papel e das consequências das suas ações.

Essa novo papel do consumidor tem colocado as organizações frente a novos conceitos relativos a forma como gerenciam e conduzem as suas atividades. Com isso, elas têm sido obrigadas a reformular sua missão, e reconhecem a importância de desenvolver uma cultura organizacional que contemple a preocupação com a ética, a solidariedade e a sustentabilidade, como princípios balizadores de suas decisões.

Nesse cenário fica evidente o papel da comunicação e da educação nesse processo, estabelecendo mecanismos que ajudem os indivíduos na tomada de consciência dessa realidade, e as organizações no desempenho de suas atividades. Tais processos comunicativos deverão ser também educativos, baseados no diálogo, na participação, no engajamento e em consonância com a visão sistêmica das organizações, como veremos a seguir.

\section{A interface comunicação-educação}

É sabido que a comunicação esta cada vez mais presente no cotidiano das pessoas, ditando modas, valores e idéias. Também não é mais novidade o interesse de instituições públicas e privadas e de organizações sociais e populares em desenvolver projetos e ações visando à chamada “educação para os meios” ou "Educomunicacão", sejam eles motivados por princípios ideológicos os mais diversos, por intenções de conscientização e formação ou até mesmo de fidelização dos públicos estratégicos.

Embora as primeiras investigações sobre as inter-relações entre os campos da comunicação e da educação remontem às décadas de 1930 e 1940, derivadas das inquietudes geradas pela expansão dos meios (CITELLI, 2002, p.101). No Brasil tais investigações ganham consistência a partir da segunda metade do século XX, em especial após a popularização das emissoras de rádio e de televisão e a criação dos cursos de comunicação social.

Mas é mesmo no contexto socioeconômico e político latino-americano do pós-guerra, que essa inter-relação começa a se consolidar e a adquirir as características que formam sua identidade. Em primeiro lugar é preciso destacar a ligação direta entre a explosão do fenômeno da comunicação de massa e o modelo capitalista de produção que buscava conquistar o mercado consumidor latinoamericano e que logo percebeu o poder de persuasão e convencimento dos meios eletrônicos em 
terras com altos índices de analfabetismo. Aos países em desenvolvimento coube a inserção na nova ordem econômica mundial a partir das representações sociais transmitidas pelas grandes emissoras de rádio e televisão.

O dualismo teórico - entre funcionalismo e teoria crítica - e político-econômico - entre o capitalismo e o socialismo - é o pano de fundo das propostas de comunicação e educação que se desenvolvem na América Latina. De um lado estão as propostas governamentais que investem em infraestrutura de comunicação para assegurar um modelo de integração nacional nos modelos de modernização desenhados pelos países dominantes. De outro, nascem propostas de educação para a comunicação, criadas por diversos tipos de instituições e pela sociedade civil organizada.

A maior parte delas, sob a influência da proposta de educação libertadora do pedagogo Paulo Freire, que "ao rever as teorias da comunicação vigentes até a década de 1970, lançou as bases para uma nova pedagogia, reafirmando a concepção da "educação para os meios" como atividade inerente aos programas de alfabetização e de educação popular" (SOARES, 1999, p. 23).

Somada à teoria da dependência ${ }^{2}$, a pedagogia de Paulo Freire impulsiona os projetos denominados de "leitura crítica dos meios", que segundo reconhecem autores como Soares (1999, p.32) e Moran (1993, p.31), tinham como interesse despertar a consciência crítica dos receptores (especialmente dos telespectadores) em relação ao que chamam de "invasão cultural".

Esse cenário começa a mudar no final dos anos 1970, quando em toda a América Latina os governos militares começam a ser derrubados ou substituídos por um movimento de redemocratização. A própria evolução das teorias da comunicação, começa a apontar para a complexidade do processo comunicacional e supera o dualismo e o radicalismo retórico entre Funcionalismo versus Teoria Crítica. No continente latino-americano os estudos de Jesús MartínBarbero sobre as mediações culturais e a influência dos estudos culturais ingleses, passam a fundamentar as novas pesquisas em comunicação que privilegiam a recepção.

O início da década de 1980 registra uma ebulição nas principais cidades brasileiras. A sociedade vai às ruas, reivindica a volta do regime democrático através de eleições diretas e as empresas de comunicação percebem a necessidade de adaptar sua programação, em especial as de conteúdo jornalístico, ao novo perfil de seus receptores.

\footnotetext{
${ }^{2}$ A chamada Teoria da Dependência é elaborada por um grupo de economistas ligados à Cepal (Comissão Econômica para América Latina), segundo a qual os países industrializados formavam o centro de um modelo de exploração de países subdesenvolvidos localizados na periferia, criando um desequilíbrio permanente e uma relação de dependência de ambos os lados. (HERCOVITZ, 1995).
} 
Esses novos aportes teóricos contribuem para a consolidação do campo da inter-relação comunicação-educação. O que nas décadas de 1960 e 1970 foi utilizado praticamente como instrumento de conscientização a serviço da luta ideológica que se travava no mundo, e especificamente na América Latina, cada vez mais se transforma em objeto de estudo nas instituições de ensino e pesquisa. Um marco nesta mudança é a criação do Núcleo de Comunicação e Educação (NCE) da USP (Universidade de São Paulo).

Uma pesquisa $^{3}$ realizada pelo NCE durante os anos de 1997 e 1998 reconhece quatro áreas concretas de intervenção social no campo da inter-relação entre comunicação e educação, apresentando uma primeira sistematização sobre o tema. São elas:

- área da educação para a comunicação, que engloba as reflexões sobre os sujeitos do processo de comunicação e os programas de formação de receptores críticos frente aos meios.

- área da mediação tecnológica na educação, que procura refletir sobre as várias possibilidades de usos das tecnologias da informação na educação.

- área da gestão comunicativa, que articula o planejamento, a execução e realização dos processos e procedimentos que se articulam no âmbito da Comunicação/Cultura, Educação, criando "ecossistemas comunicacionais" 4 .

- área da reflexão epistemológica, que analisa "a inter-relação Comunicação/educação como fenômeno cultural emergente, o que no campo da academia corresponde ao conjunto dos estudos sobre a natureza do próprio fenômeno constituído pela inter-relação em apreço" (SOARES, 1999, p. 27).

Ao relacionar as quatro áreas de inter-relação com as principais ações desenvolvidas no Brasil, pode-se observar que a primeira delas, a de educação para a comunicação, se desenvolveu principalmente junto aos movimentos sociais e populares e às pastorais ou ainda sob a organização da UNESCO. Ressalta-se, entretanto, que com as mudanças ocorridas na sociedade de um modo geral, tais organizações também passaram por um processo de reestruturação, transformando-se em ONGs.

\footnotetext{
${ }^{3}$ A pesquisa analisou um questionário respondido por 178 especialistas de 14 países ibero-americanos e 25 entrevistas realizadas junto a 25 pesquisadores e profissionais da área, sendo 12 da América Latina e 13 do Brasil. (SOARES, 1999, p.2).

${ }^{4}$ Segundo Soares (1999, p.69) "o conceito de ecossistema comunicacional designa a organização do ambiente, a disponibilização dos recursos, omodus faciendi dos sujeitos envolvidos e o conjunto das ações que caracterizam determinado tipo de ação comunicacional. (...) Os indivíduos e as instituições podem pertencer e atuar, simultaneamente, em distintos ecossistemas comunicacionais, uns exercendo influências sobre os outros.”.
} 
Já a segunda área, a da mediação tecnológica, foi uma das que mais se desenvolveu a partir dos anos 90 e a que realizou projetos através de instituições públicas. Três razões impulsionaram esse desenvolvimento. A primeira delas foi à aprovação da Lei de Diretrizes e Bases da Educação Nacional (Lei n 9394/96) e dos Parâmetros Curriculares Nacionais para Educação Fundamental (PCNs), que criam nova regulamentação e novos parâmetros para o ensino brasileiro e contemplam nos temas transversais a discussão sobre a importância dos meios de comunicação de massa, bem como mencionam a inclusão de novas tecnologias em todas as fases do ensino e até mesmo possibilitando programas de educação à distância. A segunda foi o barateamento de tecnologias digitais e a ampliação dos serviços de Internet, que ampliou o acesso à tecnologia às camadas mais pobres da população, através de diversos programas de inclusão digital e de uso da Internet em escolas públicas. Finalmente, a terceira razão, foi à institucionalização de fóruns de pesquisa na área, tais como a Sociedade Brasileira de Informação na Educação (SBIE), em 1990 (VERMELHO; PRESAS AREU, 2005, p. 1422).

Paralelamente a esse movimento de avanço nas pesquisas científicas, há no Brasil, a partir da década de 1990 uma proliferação de programas governamentais e empresariais voltados à interrelação entre educação-tecnologia e comunicação ${ }^{5}$. Em geral, atendem a uma lógica de mercado, que se concretiza em acordos do poder público com empresas privadas e são implantados sem a devida preparação dos professores envolvidos.

A área da gestão comunicativa diz respeito, segundo Soares (1999, p.41) à questão “comunicação/poder" e visa entender a especificidade da comunicação educativa e o papel de seu agente o educomunicador, "facilitador que aplica intencionalidade ao uso dos processos, recursos e tecnologia da informação a partir da perspectiva de uma mediação participativa e democrática de comunicação”. Novamente aqui é a Lei de Diretrizes e Bases, aprovada pelo Conselho Nacional de Educação que "alerta para o fato de que sem se considerar o fenômeno da comunicação, torna-se impossível ou inviável coordenar adequadamente qualquer processo educativo", como afirma Soares. (1999, p. 42). Para que isso aconteça é necessário haver uma formação adequada dos profissionais que serão os gestores de processos comunicais no espaço educativo.

A quarta e última das áreas da inter-relação comunicação-educação analisada pela pesquisa do NCE é a das reflexões epistemológicas em torno do novo campo. Essa é uma área mais

\footnotetext{
${ }^{5}$ Podemos citar como exemplo o caso da TV Escola do Governo Federal, da TV Futura mantida por um pool de 17 grandes empresas articuladas pela Fundação Roberto Marinho e de projetos que visam incentivar a utilização de jornais e revistas em sala de aula, como o da revista Veja analisado nesse artigo e o do jornal paranaense Gazeta do Povo, entre outros.
} 
complexas de ser explicitada e compreende toda a discussão teórica que envolve o próprio conceito de Modernidade. Segundo Soares (1999, p. 47), uma compreensão mais clara do conceito de Educomunicação pode ser obtida se recordarmos, como autor faz em rememoração a Mário Kaplun, os três modelos básicos de educação ainda vigentes. O primeiro deles o da educação que dá ênfase aos conteúdos; o segundo, o da educação que dá ênfase nos efeitos e o terceiro, o da educação que dá ênfase nos processos. Assim, no primeiro caso, o da ênfase nos conteúdos, tem-se a compreensão da comunicação como processo autoritário, no qual o emissor é o protagonista. No modelo que dá ênfase aos efeitos, a educação visa persuadir o educando e o receptor para uma mudança de comportamento. Finalmente, no terceiro caso, a educação que dá ênfase ao processo, busca uma interação dialética entre as pessoas e sua realidade.

\section{Educomunicação na perspectiva organizacional}

Como foi visto, mais do que modismo veiculado pela mídia, a atuação das empresas vem se intensificando no que concerne ao apoio a programas sociais e ao desenvolvimento de projetos voltados a uma causa. Tais práticas parecem estar cada vez mais integradas ao conjunto de estratégias corporativas que regem o negócio, deixando de ser uma atividade de importância secundária para a alta administração.

Outro fator determinante é a utilização ainda difusa das ações e propostas. As organizações têm dificuldade de eleger focos de atuação e utilizar competências organizacionais para obter maiores eficiência e eficácia das ações sociais promovidas e elegem os projetos na área de educação como prioridade sem ter um conhecimento teórico-metodológico da interface e de como podem responder as demandas e necessidades da organização e de seus públicos.

Reconhecendo as quatro áreas concretas de intervenção social no campo da inter-relação entre comunicação e educação, percebe-se que a sua utilização pelas organizações deve estar inserida na área da gestão comunicativa, a qual articula o planejamento, a execução e realização dos processos e procedimentos no âmbito da Comunicação, Cultura, Educação, criando "ecossistemas comunicacionais" Tais ecossistemas promoveriam:

- a (re) afirmação ou (re) construção de uma identidade corporativa sólida com a participação ativa dos colaboradores e da comunidade em que está inserida;

- a formação dirigida às pessoas que se relacionam com a empresa com implicação prática no dia-a-dia da organização; 
- a integração entre públicos estratégicos e empresa, através de unidades educativas; e ações que busquem formá-los criticamente os tornando pensadores e arquitetos dos meios de comunicação e das tecnologias da informação.

Assim, a Educomunicação propõe ações que envolvem comunidades ou instituições em programas destinados a ampliar a capacidade de expressão das pessoas e:

aplicada ao mundo empresarial surge como o meio mais adequados para fazer das organizações ecossistemas comunicativos, âmbitos de participação e de aprendizagem que permitam às pessoas que os compõem, a possibilidade de autorealização como seres chamados a uma vida significativa. Trata-se, portanto, de uma ação ética de comunicação, dirigida às pessoas e aos segmentos sociais envolvidos com a organização, e que busca desenvolvê-la como um ambiente de aprendizagem e crescimento, no qual cada indivíduo passa a ser um agente ativo e responsável de um projeto comum. (CARVALHO, 2005, p. 2).

De acordo com Soares, há dois extremos relacionados à Educomunicação nas empresas atualmente. No ambiente interno da organização, a Educomunicacão não é realizada plenamente devido à existência de hierarquia e expectativa com relação ao comportamento dos funcionários, no entanto, podem ser realizados procedimentos que se aproximam do campo educomunicativo. No outro extremo, mais relacionado com o nosso objeto de estudo, está o apoio e desenvolvimento a projetos educomunicativos com públicos estratégicos. "Estão sendo realizadas atividades significativas à medida que o setor empresarial está descobrindo a ação de organizações sociais voltadas para o campo da educação pela comunicação", afirma o autor (SOARES apud VERONEZE, 2008, s/p).

$\mathrm{Na}$ proposta educomunicativa a empresa se torna um espaço significativo no qual cada indivíduo passa a ser um elemento chave para a realização do projeto e da missão da organização. A identidade organizacional se funde com os valores e aspirações dos públicos e o âmbito dos resultados deixa de ser um fim em si mesmo, para tornar-se fruto de uma motivação que se materializa no trabalho. É precisamente este sentido recuperado no ambiente profissional que, levando ao compromisso e à atitude, tem como conseqüência natural a conquista dos melhores resultados.

Nesse ecossistema complexo o conjunto é mais que a soma das partes e a organização - mais que uma união de elementos independentes - se desenvolve como um sistema de relações carregadas de sentido e significação. Assim, qualquer divisão ou fragmentação da comunicação em 
ações isoladas e pontuais que não estejam incutidas na identidade e no DNA da empresa, passam a ser uma ação pobre e reducionista.

A Educomunicação aplicada ao mundo organizacional promoverá a (re)afirmação ou (re)construção de uma identidade corporativa sólida: não se pode pensar em formar um espaço significativo sem uma clareza do que é a organização, qual a sua essência e identidade, quais seus valores, qual sua missão e visão. Esses elementos de identidade devem ser "relidos e redefinidos" com a participação dos membros da empresa, para que sejam parte de suas vidas e, portanto, tenham sentido.

Ações que visem à formação crítica e a participação dos indivíduos em temas de interesse básicos para o seu desenvolvimento humano e social devem ser ofertadas de maneira participativa, promovendo uma inserção dos públicos na vida diária da organização, a partir de práticas reflexivas e dialógicas. Resumindo, busca-se a integração entre pessoas e empresa através de unidades educativas, meios de comunicação e tecnologia da informação, processos e práticas organizacionais que levem a tal alinhamento transformando os públicos em pensadores e arquitetos dos meios de comunicação e das tecnologias da informação, a partir de um melhor conhecimento e leitura de tais instrumentos.

Discute-se ainda a importância de um profissional, o educomunicador (mediador), que deve ser - também no caso específico dos programas aplicados à empresa - o coordenador da ação proposta, trabalhando em conjunto com profissionais de outras áreas e buscando um enfoque multidisciplinar, condição necessária para que se dê a gestão do conhecimento.

\section{O projeto "Veja na Sala de Aula"}

A escolha do Projeto "Veja na Sala de Aula" se deu, em primeiro momento, pela necessidade de utilizar um projeto nacional que se adequasse a perspectiva teórica da pesquisa. Dessa forma a partir dessa escolha inicial foi utilizada a pesquisa exploratório-descritiva apoiada em um estudo de caso. Optou-se, portanto, por essa metodologia, considerando-se primeiramente a oportunidade de análise qualitativa dos dados. A escolha por esse método visa compreender o fenômeno estudado com a finalidade de obter também algumas generalizações que, eventualmente, puderam aflorar após a análise dos resultados obtidos.

Desde 1998, a Editora Abril e a revista Veja, em parceria com a Fundação Victor Civita, implantaram o Programa "Veja na Sala de Aula". Trata-se de uma ferramenta pedagógica, que traz os fatos do Brasil e do mundo para o universo escolar. Seu maior objetivo, segundo seus criadores, 
é contribuir para o desenvolvimento dos alunos do Ensino Médio, fornecendo-lhes subsídios para que se tornem atuantes, preparados e bem informados. A missão do Programa é: "Ser uma ferramenta pedagógica complementar e diferenciada que traz os fatos do Brasil e do mundo para dentro da sala de aula".

Devido às inúmeras possibilidades de análise, direcionou-se o foco deste trabalho para uma das estratégias utilizadas e apresentadas pelo criadores do projeto como um dos diferencias: o "Guia do Professor". O "Guia do Professor" é um manual didático elaborado por uma equipe de professores e distribuído semanalmente com as edições da revista Veja para as escolas participantes, estes são elaborados por uma equipe da Fundação Victor Civita, com a colaboração de educadores especializados em suas respectivas áreas de conhecimento. Seu conteúdo disponibiliza planos de aula, sugestões de atividades, exercícios, temas para debate, textos de apoio e experiências práticas, além de bibliografia complementar, filmografia e uma seleção de sites para professores e alunos. O “Guia do Professor” oferece ainda várias ilustrações, infográficos e fotos.

\section{0 "Guia do Professor" como ferramenta (des)educomunicativa}

Utilizando o "Guia do Professor" como recorte para o estudo buscou-se entender se o seu conteúdo promove um processo de leitura crítica dos meios favorecendo consequentemente a aprendizagem e até que ponto pode ser considerado uma proposta de criação de espaços participativos e democráticos na escola.

Como já dito, um grande número de ações de responsabilidade social são apenas aparentemente "sociais", porque se pautam em concepções normativas e estáticas, preocupadas mais com a visibilidade e lucratividade do que com a transformação social. E como já se afirmou, quando prevalece apenas essa perspectiva, inibe-se a possibilidade de levar adiante uma proposta educomunicativa real.

Em primeira análise verificou-se que a estrutura e a proposta de aplicação do "Guia do Professor" se alinham a perspectiva moderna da escola e as premissas da Educomunicacão, pois, prioriza-se uma harmonização entre as necessidades dos alunos e os valores sociais a partir de conceitos como: participação, responsabilidade, criatividade, e resolução de problemas.

A disposição dos elementos verbais e não verbais das capas são na maioria das vezes, estruturados dentro de um padrão que prioriza as imagens chamando a atenção do leitor para a ferramenta e despertando assim um interesse na sua utilização. O uso de imagens produz uma maior apreensão e entendimento aos conteúdos, bem como incentivam e aguçam a curiosidade, é ainda 
um diferencial no ambiente escolar que privilegia a linguagem verbal (escrita e oral) em detrimento de outras linguagens.

Os Planos de aula sempre são iniciados com a discriminação da área de conhecimento, a disciplina trabalhada, e o título da matéria da Revista Veja com suas respectivas páginas. O discurso inicial dos planos tende a despertar uma curiosidade para a leitura e inserir no texto um ou mais modos de como o professor pode explorar àquele conteúdo, delimitando as habilidades, competências e o tempo estimado para desenvolvimento.

Observou-se, também, que o "Guia do Professor" opta por uma comunicação dedutiva que valoriza mais a reflexão em lugar da memorização. Assim, o papel do professor não é só visto por um ângulo de sua competência de estruturar a comunicação, mas também de escutar, facilitando as articulações necessárias entre "conhecimentos e competências" por um lado e bases vivenciais e culturais do aluno, por outro. A leitura da reportagem da revista mais a introdução do plano de aula e a preparação para as atividades demonstram a preocupação em inserir o aluno no ambiente da aprendizagem.

Os planos de aula obedecem a uma estrutura flexível já que cada proposta contém um número de elementos fixos e outros que se organizam de acordo com o conteúdo abordado e os recursos escolhidos. Percebe-se que a intenção é oferecer uma amostragem das informações e processos sociais e profissionalmente relevantes, na esperança de que, a partir dessa amostragem, os alunos desenvolvam competências para tratar do que subseqüentemente lhes pareça importante, sem, no entanto fugir daquilo que está escrito na revista ou no "Guia do Professor".

Outro recurso utilizado que merece destaque é a proposta de ações pedagógicas interdisciplinares e multidisciplinares. Sabe-se que esses dois termos são extremamente difundidos e incentivados no ambiente escolar, porém as suas aplicações tendem a não conseguir transpor o plano teórico, gerando insatisfação tanto para professores como para os alunos. Assim, o "Guia do Professor" procura ampliar as informações disponíveis, proliferando-se imagens e interações criando contato entre áreas apoiadas em códigos verbais e não verbais.

No entanto, mesmo atestando que o "Guia do Professor" foi constituído a partir de intenções educomunicativas como as citadas acima surgem importantes indagações:

1. Será que apenas essas intenções constituem elementos suficientes para a criação de ecossistemas que integrem os sujeitos buscando formá-los criticamente, tornando-os pensadores e arquitetos dos meios de comunicação e das tecnologias da informação? 
2. Será que um modelo fixo (“Guia do Professor”) para uso da mídia na escola é capaz de promover sujeitos críticos e inseridos no seu próprio meio social garantindo um espaço democrático e cidadão?

Obviamente que não, o "Guia do Professor" é apenas um elemento do processo e isoladamente não garante o sucesso da iniciativa. Sabe-se que no ambiente da sala de aula há uma multiplicidade de signos envolvidos que interagem no processo de aprendizagem e certamente o influenciam e por ele são influenciados. Dentre todos, a atuação do professor, enquanto mediador, pode ser considerado um elemento fundamental.

É essencial que o professor, na utilização do "Guia do Professor" em sala de aula, domine o conteúdo, reconheça a proposta do Programa "Veja na Sala de Aula" e, consequentemente, os recursos por ele oferecidos, para que haja convergência de interesses e prevaleçam os objetivos da aprendizagem. Dessa forma, mesmo tendo o "Guia do Professor" como modelo a ser seguido o professor deve saber contextualizá-lo de forma crítica para que este não se torne uma verdade absoluta, algo nocivo e contrário ao modelo de educação libertadora, principalmente no cenário de grande dominação das empresas de comunicação na atualidade.

O seu uso deve estar associado à revista, mas também relacionado a outras fontes, propondo assim um olhar alternativo para os conteúdos. Essa possibilidade permite que o aluno consiga visualizar que a aprendizagem pode acontecer com informações correlacionais e proporcionará um ambiente mais interessante para a aquisição de conhecimentos. Essa iniciativa cria unidades educativas abertas e democráticas e conduz o aluno ao desenvolvimento de uma competência fundamental nos dias de hoje que é a construção da aprendizagem por seu próprio esforço de busca, seleção e sistematização das informações (aprender a aprender), premissa básica da Educomunicacão.

Outro ponto a ser questionado é a importante conexão pelo professor dos conteúdos com o contexto sócio-cultural dos alunos. O simples uso do "Guia do Professor" não conseguirá isoladamente desconfigurar o isolamento tradicional do ambiente escolar, somente a mediação adequada promoverá temperaturas mais quentes e estabelecerá pontos de conexão com a cultura que está do lado de fora, que é local e não global.

Apresenta-se assim a importância das relações entre escola e cultura no processo educomunicativo. As organizações precisam se atentar que todo projeto na perspectiva da Educomunicacão deve estar imerso na cultura e, particularmente, no momento histórico em que se 
situa. A reflexão sobre essa temática é co-extensiva ao próprio desenvolvimento do pensamento pedagógico.

Não se pode conceber uma experiência pedagógica em que a referência cultural não esteja presente. A escola é, sem dúvida, uma instituição cultural. Portanto, as relações entre escola, cultura e meios de comunicação não podem ser concebidas isoladamente, mas sim como universos entrelaçados, como uma teia tecida no cotidiano e com fios e nós profundamente articulados.

Os alunos não devem só absorver os conteúdos, mas devem interagir com eles, reagindo e interpretando. E interpretar nada mais é do que usar o seu acervo cultural para processar interpelações recebidas. Assim, mesmo sabendo que na educação e em qualquer processo comunicacional existem boas e más interpretações, deve-se destacar que o saldo seja ele positivo ou não, já pode ser considerada aprendizagem.

Outro ponto importante se dá no fato de que a simples menção no "Guia do Professor" para que se analisem os argumentos da revista e peça a opinião da turma, ou contextualize o conteúdo de determinada reportagem e seus desdobramentos, ou ainda analise com os alunos as implicações de um determinado fenômeno e reflita sobre as possibilidades já existentes não estabelece um ambiente participativo e dialógico. Essa dialogia deve emergir das trocas simbólicas entre os sujeitos e não apenas de um modelo fixo adotado pelo mediador.

\section{Considerações finais}

Não há duvidas que esse seja o momento ideal para repensar o sentido do trabalho nas organizações, isso compreende unir objetivos que por muito tempo estiveram separados pela "ruptura" positivista: o campo social e ético da realização pessoal, e o campo pragmático dos "resultados", do crescimento econômico, do lucro e da "eficiência" organizacional.

Nessa perspectiva de unir âmbitos tão divergentes, um programa de responsabilidade social comprometido com a educação dos indivíduos e com a aprendizagem da organização, é a chave para a criação de um ecossistema mais humanizado e menos focado no viés econômico e racional que prevaleceu por tanto tempo na história das organizações.

É nesse contexto que a Educomunicação surge como um campo estratégico, que deve ser investigado e aprofundado como um caminho de excelência para fazer do âmbito profissional um universo significativo. Um novo tipo de processo comunicativo que ajude a reavaliar os parâmetros éticos e construir uma sociedade melhor. Em resumo, a Educomunicacão tem como meta construir 
a cidadania, a partir do pressuposto básico do exercício do direito de todos à expressão e à comunicação.

Há uma mudança clara nos objetivos das propostas de leitura crítica de um e outro período, mas permanece a necessidade de se ter um leitor capaz de ler e emitir opinião sobre tudo aquilo que lhe é apresentado. Toda proposta de leitura crítica traz à tona a discussão do que é ser crítico. Se para os projetos dos anos de 1960 ser crítico era discordar do regime político autoritário e alinhado a alguns países de primeiro mundo, para os de 2012, o desafio se torna mais complexo e as empresas que os desenvolvem sabem disso.

A criticidade almejada antes e agora, se realmente atingida, não pode ser manipulada. $\mathrm{O}$ ser crítico e consciente exerce sua vontade e autonomia. A revisão história dos projetos de leitura crítica e a análise de dois projetos atuais apontam para o papel dos meios de comunicação na sociedade, que como afirma Wolton, cada vez mais é o ser a linha tênue que sustenta toda democracia.

Como recurso educomunicativo percebeu-se que o projeto "Veja na Sala de Aula" representa uma alternativa para aulas mais dinâmicas, criativas e interessantes, preenchendo uma lacuna crucial nos processos de aquisição de conhecimentos, mas não se pode afirmar que a iniciativa seja a solução para questões tão complexas como a desterritorialização da aprendizagem, a adaptação do ensino à proliferação de novas linguagens, a abundância de informação, a manipulação dos indivíduos pelos meios e o entendimento da escola espaço social e cultural.

Conclui-se assim, que tão importante quanto uma ferramenta educomunicativa na formação de indivíduos mais críticos e inseridos no seu ambiente social é a presença de mediadores, que criem ambientes favoráveis a essas novas possibilidades. Cabe ao mediador da comunicação o papel de relacionar os conteúdos ao contexto sócio-cultural privilegiando a leitura crítica e a aprendizagem à intenção muitas vezes reducionista, manipuladora e comercial dos projetos.

Para isso se faz necessário transformar a ação comunicativa proposta pelo professor, que na maioria das vezes se resume em transmissor de informações, para um agente transformador capaz de ser o leitor crítico das iniciativas e utilizá-las adequadamente.

Artigo submetido em 05/12/2012 e aceito em 11/03/2013.

\section{Referências}


ASHEN, Melvin. Changing the social contract: a role for business. Journal of World Business, Columbia, v. 5, p. 6-10, nov./dez. 1970.

BORGER, F.G. Responsabilidade social: efeitos da atuação social na dinâmica empresarial, 2001. Tese (Doutorado em Administração). Departamento de Administração da Faculdade de Economia, Administração e Contabilidade da Universidade de São Paulo, São Paulo, Brasil.

BUCHHOLZ, Rogene. Business environment andpublic policy: implications for management and strategy formulation. New Jersey: Prentice Hall, 1989.

BUENO, W.C. Comunicação Empresarial: teoria e prática. São Paulo: Manole, 2003.

CARROLL, A.B. A Three-Dimensional Conceptual Model of Corporate Social Performance. Academy of Management Review, v. 4, p. 497-505, 1979.

CARVALHO, Paulo Monteiro de. Educomunicação e a reinvenção da empresa do século XXI. Disponível em: <http://www.rh.com.br/Portal/Comunicacao/Artigo/4002/educomunicacao-e-areinvencaoda-empresa-do-seculo-xxi.html>. Acesso em: 20 jan. 2001.

CITELLI, Adilson. Comunicação e educação: aproximações. In: BACCEGA, Maria Aparecida (Org.). Gestão de Processos Comunicacionais. São Paulo: Atlas, 2002.

HERSCOVITZ, Heloiza. A Pesquisa em Comunicação na América Latina: desafios nos anos 90. Comunicação \& Sociedade, São Bernardo do Campo SP ano XIII, n. 23, Editora IMS, jun. 1995, p.111-128.

LUHMANN, Niklas. La sociedad de la sociedad. México: Herder, 2007.

MORAN, José Manuel. Leituras dos meios de Comunicação. São Paulo: Pancast, 1993.

PRESTON, L. Corporation and society: the search for a paradigm. Journal of Economic Literature, p. 435-453, 1975.

SOARES, Ismar de Oliveira. Metodologias da educação para comunicação e gestão comunicativa no Brasil e na América Latina. In: BACCEGA, Maria Aparecida (Org.). Gestão de processos comunicacionais. São Paulo: Atlas, 2002. p.113-132.

SOARES, Ismar de Oliveira. Comunicação/Educação: A emergência de um novo campo e o perfil de seus profissionais. In: Revista Contato, Brasília, DF, ano 1, n. 2, jan./mar. 1999, p. 19-74.

VERMELHO, S.C.; AREU, G.I.P. Estado da arte da área de educação comunicação em periódicos brasileiros. Educação \& Sociedade, Campinas, v. 26, n. 93, set./dez. 2005. Disponível em: $<$ http://www.scielo.br/scielo.php?script=sci_arttext\&pid=S0101-73302005000400018\&lng= pt\&nrm=iso $>$. Acesso em: 15 mar. 2011. 
VERONEZE, Ademir. Ismar Soares e a Educomunicação nas corporações: entrevista do prof. Ismar. Disponível em: <http://educomambiental.blogspot.com/2008/11/ismarsoares-e-educomunica cao-nas.html>. Acesso em: 12 jan. 2008.

WARTICK, S.; COCHRAN, P. The evolution of the corporate social performance model. Academy of Management Review, v. 10, n. 4, p. 758-768, 1985. 